\title{
Instagram Source Effects: The Impact of Familiarity and Likeability on Influencer Outcomes
}

\author{
Susan Myers \\ University of Central Arkansas
}

Research confirms that over 70\% of American adults actively engage on social media (Pew Research, 2019). As social media use grows, marketers continue to invest heavily in digital strategies including influencer marketing (Balilis, 2020). These influencers have created a new economy where brands pay to tap into the connections they have with followers. This study extends the source attractiveness model to top Instagram influencers using data from You.gov to measure familiarity and likeability of a sample of 82 top Instagram influencers with between 20 and 200 million followers. Findings suggest that these source characteristics impact the number of followers and engagement with content. Specifically, the results indicate that more familiar influencers had more followers but lower engagement while more likeable influencers had fewer followers but higher engagement. This indicates that familiarity and likeability may lead to different social media outcomes.

Keywords: influencer marketing, familiarity, likeability, engagement rate, Instagram

\section{INTRODUCTION}

Digital opportunities are transforming consumption unlike ever before. The stage has been set for a digital world where consumers can work, shop, learn, meet, date, and exist through online connections in a virtual world. Social media continues to grow in likeability as a way both to consume and create experiences. Youtube sees more than 1.6 billion visits per month and social media platforms Twitter, Facebook, Reddit, Pinterest, Instagram and LinkedIn are all in the top 20 most visited websites in the US (Hardwick, 2020). Social media's power and influence continues to expand and it is likely to continue in the future. According to Pew Research, 36\% of American adults used at least one social media site in 2009, but, 10 years later, that number had doubled to $72 \%$ (2019). Social media dominates the $18-29$ range where usage reached $90 \%$ by 2019 . The research also indicates the ubiquity of social media by race, gender, education and community size. While Youtube and Facebook are the most widely adopted platforms, Instagram holds $67 \%$ of the young adult audience.

As social media usage among US consumers has grown, so has its importance to brands. It has emerged as a key element for building brand awareness, connection and loyalty. Companies of every size have embraced the importance of a social media presence beyond the traditional brand website model. Almost any website visited will have links for the user to connect on social media. Some brands like Skittles (www.skittles.com) make redirection to social media the primary purpose of the owned homepage. A website is a static representation of the brand while social media offers a conversation. 
This relationship between consumers and brands is further magnified by an economy of influencers working to create connections. Influencer marketing (IM) is growing at a lightning pace with expenditures in 2020 increasing by as much as 65\% (Bailis, 2020). Advertisers are clearly changing how they connect, engage and build trust with their customers while synchronously masquerading their advertising appeals (Campbell, Mohr and Verlegh, 2013). IM investment was predicted to reach $\$ 10$ billion in 2020, and annual growth of SMA has topped 50\% each year since 2016 (Influencer Marketing Hub, 2020).

\section{LITERATURE REVIEW}

\section{Social Media Platforms}

Facebook, Instagram, and Twitter are the largest global social media platforms. Within the U.S., Facebook $69.1 \%$ of the population is expected to have adopted facebook by 2025 (Chen, 2021). Similarly, Twitter has seen a steady growth since 2006 with about 330 million active users as of 2019 (Iqbal, 2020). A more recent social media stable, Instagram launched in 2010 as a visual focused platform with images or videos that include text captions. Instagram expects to reach 117.21 million U.S. users by the end of 2021 (Newberry, 2019). Instagram posts may include the same elements as Facebook posts and Tweets, but a visual component (i.e., a picture or video) is required. Instagram allows up to 10 photos and multiple videos per post (within a two minute, 20-second length limit) and has a character limit of 2,200 for post captions. Instagram does not allow hyperlinks to outside content and, while users can like and comment on posts, there is no integrated option to share content within the platform (unlike Facebook and Twitter).

\section{Engagement}

Marketing research tends to define social media engagement based on the behaviors within the platform, such as likes, comments, and shares on Facebook (e.g., Blowers, 2012). These individual interactions can be useful performance indicators of audience response to a given piece of content. Engagement rate is a "formula that measures the amount of interaction social media content earns relative to reach or other audience figures" (Hootsuite 2019). The formula considers the account's followers allowing comparison across accounts of various sizes (Influencer Marketing Hub 2020). The engagement rate formula typically considers the number of post interactions (e.g., likes, shares, comments) divided by the total number of account followers (Hootsuite, 2020).

\section{The Source Attractiveness Model}

The use of celebrities in campaigns is a common practice for advertisers. McCracken's (1989, pl 310) defined a celebrity endorser as 'any individual who enjoys public recognition and who uses this recognition on behalf of a consumer good by appearing with it in an advertisement. As a popular research stream, studies consistently highlight the role of celebrities in persuasion and indicate that celebrity endorsements lead to positive brand outcomes (Ohanian, 1991; Amos, Holmes and Strutton, 2008). Research on the S-A model has demonstrated that attractive celebrity endorsers enhance attitudes towards advertising and brands while their effect on behavior is uncertain (Erdogan, 1999). While physical attractiveness is the most researched area of attractiveness, multiple models posit that source attractiveness is a multidimensional construct linking many qualities of the endorser including similarity, familiarity and likeability to the effectiveness of a message (McGuire, 1985; Triandis, 1971). Similarity is a perceived resemblance between the source and the receiver; familiarity arises from repeated exposure that creates associations and knowledge of the source; and Likability reflects an affection that the consumer holds toward the endorser. This conceptualization means that source attractiveness encompasses a wide range of personal and personality characteristics beyond physical appearance (Erdogan 1999).

There is considerable evidence that physically attractive endorsers enhance persuasion (Till and Busler 2000; Kahle \& Homer, 1985; Eagly et al., 1991), but there are indications that the other elements of attractiveness play a role in ad and brand evaluations. In his literature review, Joseph (1982) concluded that attractive sources are liked more than unattractive sources suggesting that the impact on persuasion works through the similarity, familiarity and likability factors of the S-A model. Prior research has also shown 
that people consider those who are similar to themselves to be more likable than people who are dissimilar (Lynch and Schuler 1994). Similarly, familiarity has been linked to better persuasive outcomes (GarciaMarques and Mackie 2001) and stronger purchase intentions (Carrillat, d'Astous and Lazure, 2013; Fleck, Korchia \& Le Roy, 2012). Overall, whether evaluated on physical qualities, personality or status, source attractiveness motivates persuasion by increasing consumer identification (Belch and Belch, 1995).

\section{Influencer Marketing}

Social media has blurred the lines between celebrity endorsement and influencer marketing. Influencers serve as their own category of people who were unknown to the public before building their careers on social media, but traditional celebrities are also on social media--actors, athletes, musicians and public figures use their influence to promote products; however, there are key differences between endorsers and influencers in content creation and audience relationships. In endorsement deals, the celebrity is the face of the brand and relays the message that the brand produces. For instance, Lebron James is a Nike endorser, but we do not expect Lebron to write Nike commercials. In Influencer marketing, the celebrity is the perceived creator of the message. Consider soccer great Christiano Ronaldo. While he holds an endorsement deal with Nike through traditional advertising, he also has over 58 million Twitter followers and 120 million Facebook followers. Across his platforms, it is estimated that over $20 \%$ of his posts promote Nike with a hashtag, mention, or logo (Adamson 2020). The post or photo comes from the celebrity through his or her social media presence. It is a marked hybrid of celebrity and influence. Another key difference is in the relationships. While a traditional model of celebrity endorsement focuses on connecting the familiarity of the celebrity to the brand, influencer marketing capitalizes on the relationship between the influencer and the fan. This includes meaningful interaction with the fans.

It is also important to note that celebrities serve as human brands (Thomson 2006). They often manage their individual brands through their social media accounts. So, while celebrities may represent other brands and causes, they are also their own brand. Justin Bieber and Kanye West have streetwear collections. Dr. Dre and Ray J are rappers turned tech entrepreneurs. The music industry may actually be the most obvious example of celebrities as brands. Musicians create a product in their music that is directly sold under their brand name. Even without clothing lines and headphones--musicians rely on their brand for success. As much as any,the music industry has been transformed by digitalization, and the industry's promotional strategy is now embedded in digital platforms and social media that operates through self branding. Artists build and cultivate their digital reputation because likes and comments indicate a brand that is known and appreciated.

One reason for the growth of IM is the demonstrated effects on consumer behaviors. One survey found that respondents were using social media as a primary source of information about products and services and that almost $72 \%$ of the 2000 customers surveyed noted that they follow influencer recommendations for products. Similar research has shown that a vast majority $(82 \%)$ of consumers agree that they appreciate seeing recommendations from influencers with over a third $(37 \%)$ noting that they do not mind brand content in posts as long as the content is authentic (Rimmer 2019).

Based on our review of the literature above, we predict that familiarity and likeability will positively influence followers' social media interaction with celebrity influencer posts through the S-A model.

\section{H1: Familiarity will have a positive influence on a) followers b) ER.}

\section{H2: Likeability will have a positive influence on a) followers b) ER}

\section{METHODS}

Our sample was chosen from the top Instagram profiles based on total followers. The top 350 sites were considered. The population was restricted based on several inclusion criteria. First, only individual influencer accounts were included in the sample. This removed brands and other organizations. Additionally, influencer accounts needed to enable comments and post in English. Further, YouGov scores 
were used to calculate familiarity and likeability, so only influencers with YouGov data were included in the sample. Instagram information for each of these influencers was gathered from a third-party Instagram API for the 2019 calendar year. After excluding influencers with fewer than 10 posts in the time frame, there was a final sample of 82 influencers for the analysis.

The dependent variables for the study were follower count and ER. Followers count was the number of followers for each influencer at the time of the data collection. ER was calculated per post by the following formula: (total likes for analyzed period + total comments for analyzed period/count of followers/count of posts for analyzed period. The follower count ranged from 20,917,681 to 200,768,627 with an average of $62,733,876$ ER ranged from .166 to 15.12 with a mean of 3.68 .

The independent variables were gathered from yougov.com. The YouGov sample mirrors the US demographics and is weighted to be nationally representative. Each variable they rate is calculated by taking the proportion of people who view something positively and showing it as a percentage of all of the people who have given any opinion about that thing. Since the essence of familiarity is being known, we operationalize it with the "have heard of" variable from YouGov. We operationalized likeability as the difference between the positive and negative sentiment scores. The average familiarity score was 73.49 ranging from 24 to 98 . The mean likeability score was 22.57 ranging from -41 to 69 .

\section{Results}

The primary study hypotheses were tested with MANCOVA using the general linear model tool in SPSS. The outcome variables of Follower count and ER were log-transformed to reduce skewness Familiarity and likeability were the dependent variables in the mode. The adjusted R squared values in the model were .363 for followers and .078 for ER. Familiarity had a significant positive effect on followers (f $=42.96, \mathrm{p}<.05 ; \mathrm{B}=.007)$, but a significant negative effect on $\mathrm{ER}(\mathrm{f}=6.16, \mathrm{p}<.05 ; \mathrm{B}=-.006)$. This supports $\mathrm{H} 1 \mathrm{a}$, but is counter to H1b. Likeability had a significant negative effect on followers $(\mathrm{f}=15.88, \mathrm{p}<.05$; $\mathrm{B}$ $=-.004)$, but a significant positive effect on ER $(f=5.02, p<.05 ; B=.005)$. This contradicts H2a, but supports H2b. The results are presented in Table 1.

TABLE 1

\section{EFFECTS OF FAMILIARITY AND LIKEABILITY}

\begin{tabular}{|c|c|c|c|c|c|c|}
\hline Source & $\begin{array}{l}\text { Dependent } \\
\text { Variable }\end{array}$ & $\begin{array}{r}\text { Type III Sum } \\
\text { of Squares } \\
\end{array}$ & df & Mean Square & $\mathrm{F}$ & Sig. \\
\hline \multirow[t]{2}{*}{ Corrected Model } & Followers & $2.543^{\mathrm{a}}$ & 2 & 1.271 & 24.100 & .000 \\
\hline & ER & $1.844^{\mathrm{b}}$ & 2 & .922 & 4.4404 & .015 \\
\hline \multirow[t]{2}{*}{ Intercept } & Followers & 387.520 & 1 & 387.520 & 7346.165 & .000 \\
\hline & ER & 3.142 & 1 & 3.142 & 15.007 & .000 \\
\hline \multirow[t]{2}{*}{ Familiarity } & Followers & 2.266 & 1 & 2.266 & 42.961 & .000 \\
\hline & ER & 1.289 & 1 & 1.289 & 6.159 & .015 \\
\hline \multirow[t]{2}{*}{ Likeability } & Followers & .838 & 1 & .838 & 15.883 & .000 \\
\hline & ER & 1.051 & 1 & 1.051 & 5.022 & .028 \\
\hline \multirow[t]{2}{*}{ Error } & Followers & 4.167 & 79 & .053 & & \\
\hline & ER & 16.539 & 79 & .209 & & \\
\hline \multirow[t]{2}{*}{ Total } & Followers & 4861.563 & 82 & & & \\
\hline & ER & 28.215 & 82 & & & \\
\hline \multirow[t]{2}{*}{ Corrected Total } & Followers & 6.710 & 81 & & & \\
\hline & ER & 18.383 & 81 & & & \\
\hline
\end{tabular}

a. $\quad$ R Squared $=3.79$ (Adjusted R Squared $=.363$ )

b. $\quad$ R Squared $=.100$ (Adjusted R Squared $=.078$ ) 


\section{DISCUSSION}

This study looks to understand the relationship between familiarity and likeability on social media outcomes for Instagram influencers. The results showed more familiar influencers had more followers and lower engagement while more likeable influencers had fewer followers, but higher engagement. It is clear that an influencer's level of exposure through the U.S. audience and the sentiment toward the artist are related to their social media presence. The results suggest that familiarity alone may not be a good gauge for choosing IM partners since familiarity showed a negative effect on Instagram engagement. Familiarity gives no gauge of valence, and consumers may be aware of a celebrity or influencer based on controversial things they say or do. Additionally, this high level of fame may make the influencer seem unreachable and discourage engagement. On the other hand, likeability does not translate into followers, but significantly impacts engagement. This is reasonable considering that likeability in the form of positive sentiment gives no gauge of the quantity of fans, but may suggest that these fans are genuinely interested in the influencer's views and opinions. Understanding engagement is important for influencers trying to build their social media brand equity and critical for brands planning to invest resources in brand partnerships

\section{REFERENCES}

Adamson, A. (2020). After Clooney, Ronaldo, and Selena? The next challenge for brands and celebrities. Branding Magazine. Retrieved from https://www.brandingmag.com/2020/02/11/after-clooneyronaldo-and-selena-the-next-challenge-for-brands-and-celebrities/

Amos, C., Holmes, G., \& Strutton, D. (2008). Exploring the relationship between celebrity endorser effects and advertising effectiveness: A quantitative synthesis of effect size. International Journal of Advertising, 27(2), 209-34.

Blowers, H. (2012). Measuring social media and the greater digital landscape. Computer in Libraries, $32(7), 27-29$.

Campbell, M.C., Mohr, G.S., \& Verlegh, P.W.J. (2013). Can disclosures lead consumers to resist covert persuasion? The important roles of disclosure timing and type of response. Journal of Consumer Psychology, 23(4), 483-495. https://doi.org/10.1016/j.jcps.2012.10.012

Carrillat, F.A., d'Astous, A., \& Lazure, J. (2013). For better, for worse? What to do when celebrity endorsements go bad. Journal of Advertising Research, 53(1), 15-15.

Chen, J. (2021). 20 Facebook Stats to Guide Your 2021 Facebook Strategy. Sprout Social. Retrieved from https://sproutsocial.com/insights/facebook-stats-for-marketers/

Eagly, A.H., Ashmore, R.D., Makhijani, M.G., \& Longo, L.C. (1991). What is beautiful is good, but...: A meta-analytic review of research on the physical attractiveness stereotype. Psychological Bulletin, 110(1), 109-128. https://doi.org/10.1037/0033-2909.110.1.109

Erdogan, B.Z. (1999). Celebrity endorsement: A literature review. Journal of Marketing Management, 15, 291-314.

Fleck, N., Korchia, M., \& Le Roy, I. (2012). Celebrities in advertising: Looking for congruence or likability? Psychology \& Marketing, 29(9), 651-662. https://doi.org/10.1002/mar.20551

Garcia-Marques, T., \& Mackie, D.M. (2001). The feeling of familiarity as a regulator of persuasive processing. Social Cognition, 19(1), 9-34. https://doi.org/10.1521/soco.19.1.9.18959

Hardwick, J. (2020). Top 100 most visited websites by search traffic. AHREFS Blog. Retrieved from https://ahrefs.com/blog/most-visited-websites/

Hootsuite. (2019). All the Different Ways to Calculate Engagement Rate. Retrieved from https://blog.hootsuite.com/calculate-engagement-rate/

Hootsuite. (2020). 19 Social Media Metrics That Really Matter-And How to Track Them. Retrieved from https://blog.hootsuite.com/social-media-metrics/

Influencer Marketing Hub. (2020). The state of influencer marketing 2020: Benchmark report. Retrieved from https://influencermarketinghub.com/influencer-marketing-benchmark-report-2020/ 
Iqbal, M. (2020). Twitter revenue and usage statistics. Retrieved from https://www.businessofapps.com/data/twitter-statistics/

Joseph, W.B. (1982). The credibility of physically attractive communicators: A review. Journal of Advertising, 11(3), 15-25.

Khale, L.R., \& Homer, P.M. (1985). Physical attractiveness of the celebrity endorser: A social adaptation perspective. Journal of Consumer Research, 11, 954-961.

Lynch, J., \& Schuler, D. (1994). The matchup effect of spokesperson and product congruence: A schema theory interpretation. Psychology and Marketing, 11(5), 417-445.

McCracken, G. (1989). Who is the celebrity endorser? Cultural foundations of the endorsement process. Journal of Consumer Research, 16(3), 310-321. Retrieved June 11, 2021, from http://www.jstor.org/stable/2489512

McGuire, W.J. (1985), Attitudes and attitude change. In G. Lindzey \& E. Aronson (Eds.), Handbook of Social Psychology (Vol. 2, pp. 233-346). NY: Random House.

Newberry, C. (2019). 37 Instagram stats that matter to marketers in 2020. blog.hootsuite.com. Retrieved from https://blog.hootsuite.com/instagram-statistics/

Ohanian, R. (1991, February/March). The impact of celebrity spokespersons' perceived image on consumers' intention to purchase. Journal of Advertising Research, 31, 46-54.

Pew Research. (2019). Social media fact sheet. Retrieved from https://www.pewresearch.org/internet/fact-sheet/social-media/

Thomson, M. (2006). Human brands: Investigating Antecedents to consumers' strong attachments to celebrities Journal of Marketing, 70(3), 104-119. doi:10.1509/jmkg.70.3.104

Till, B.D., \& Busler, M. (2000). The match-up hypothesis: Physical attractiveness, expertise, and the role of fit on brand attitude, purchase intent and brand beliefs. Journal of Advertising, 14(3), 1-13.

Triandis, H.C. (1971). Attitude and attitude change. New York: John Wiley \& Sons, Inc. 